\title{
ФАКТОРЫ, ВЛИЯЮЩИЕ НА ДИФФУЗИЮ НОВОЙ МОБИЛЬНОЙ ТЕХНИКИ (НА ПРИМЕРЕ СМАРТФОНОВ)
}

\author{
Дубинина М.Г.
}

Статья посвящена анализу факторов, влияющих на распространение смартфонов по странам мира и регионам Российской Федерации, а также построению моделей зависимости количества смартфонов на 100 жителей от сочиально-экономических показателей (доходов, уровня развития телекоммуникационной инфраструктуры и человеческого капитала).

DOI: $10.20537 /$ mce2019econ12

Введение. В последнее время мобильная техника получила широкое распространение во всех сферах человеческой жизни. Мобильные устройства (в том числе смартфоны и планшеты) развиваются как в качестве потребительских товаров, так и для профессиональной деятельности, являясь основным средством доступа в интернет для большинства пользователей (в 2017 г. на них приходилось более 70\% времени, проведенного пользователями в интернете). По оценкам компании Тhe Radicati Group, в 2014 г. в мире насчитывалось около 5.7 млрд пользователей мобильных устройств и более 7.7 млрд самих устройств (в среднем, 1.36 устройства на 1 пользователя [1]). В 2016 г. мировые продажи мобильных устройств оценивались в 1.4 трлн долл. [2].

В настоящее время к мобильным устройствам относятся смартфоны, планшетные компьютеры (или просто планшеты), портативные персональные компьютеры, электронные книги, игровые консоли. Беспроводной доступ к интернету, увеличенное время автономной работы и более удобная эргономика стали факторами, способствующими росту популярности этих мобильных устройств. Среди них важное место занимают смартфоны.

Мировой рынок смартфонов. Смартфоны отличаются от предыдущих поколений мобильных телефонов наличием сложных функций, поддерживающих доступ в интернет и электронную почту, просмотр

\footnotetext{
* Работа выполнена при частичной поддержке гранта РФФИ №17-06-00163
} 
потокового видео/аудио, обмен текстовыми сообщениями. Они снабжены глобальной системой определения местоположения (GPS), навигацией, возможностью управления персональной информацией, доступа к корпоративным базам данных и системам бизнес-аналитики.

В 2013 г. число пользователей смартфонов в мире превысило 1 млрд человек, в 2016 г., согласно оценкам, их количество в расчете на 100 человек жителей составило около 50 [3], при этом наибольшее значение показателя получено для Сингапура (72.3), Норвегии (67.4) и Южной Кореи (65.9).

Когда смартфоны впервые появились на рынках, их цена (около 1000 долл.) сделала их недоступными для большинства людей во всем мире. Появление дешевых смартфонов (менее чем за 40 долл.) привело к их повсеместному распространению. По данным Pew Research Center, в 17 наиболее развитых странах количество смартфонов на 100 жителей в период 2013-2017 гг. оставалось примерно одинаковым (72), тогда как в 19 развивающихся странах оно выросло с 24 в 2013 г. до 42 в 2017 г. [4].

По темпу прироста количества пользователей смартфонов в 2016 г. Россия занимала 17 место, по количеству пользователей на 100 жителей страны - 24-е из 40 рассмотренных стран.

Высокие показатели диффузии смартфонов объясняются разными причинами. Предоставляемая смартфонами возможность оставаться на связи в любое время и в любом месте отвечает современной тенденции к мобильности трудовых ресурсов. Многие мобильные приложения не только работают, но и производят данные (например, геолокационные), которые собираются и используются в многочисленных мобильных приложениях и услугах (в основном в режиме реального времени), таких как онлайн-карты, для мобильной розничной торговли и др.

Конвергенция между технологиями беспроводной связи и здравоохранением, а также более широкое использование смартфонов для мониторинга состояния здоровья перестраивают сектор здравоохранения и открывают новые рынки с большим потенциалом роста. Смартфоны, в частности, предлагают возможности интенсивного самоконтроля, обратную связь, заблаговременную клиническую поддержку пациентов. В 2014 г. 62\% владельцев смартфонов в США, согласно опросу, отслеживали не менее одного показателя здоровья (например, вес, физическую нагрузку, режим питания) [5]. 
Производители смартфонов особое внимание уделяют разработке персонализированных приложений (например, виртуальный личный помощник, умный будильник, планировщик и др.). Согласно исследованию компании Gallup, в октябре 2017 г. 47\% пользователей смартфонов в США пользовались услугами виртуального личного помощника [6].

Моделирование влияния социально-экономических факторов на диффузию смартфонов по странам. Проблемы моделирования диффузии информационно-коммуникационных технологий рассматривались во многих работах отечественных исследователей, при этом особое внимание уделялось социально-экономическим факторам, влияющим на скорость распространения этих технологий [6-9].

Темпы распространения смартфонов также во многом определяются экономическими и социальными факторами. Несмотря на важную роль смартфонов в современном мире, темп прироста числа новых пользователей в 2016 г. снизился для всех рассмотренных стран (см. табл. 1).

Таблица 1. Темп прироста количества пользователей смартфонов в расчете на 100 жителей в ряде стран, в \% к предыдущему году (рассчитано по данным $[10,11])$.

\begin{tabular}{|c|l|c|c|}
\hline № п/II & \multicolumn{1}{|c|}{ Страна } & $\mathbf{2 0 1 5}$ & $\mathbf{2 0 1 6}$ \\
\hline 1 & Индия & 34.59 & 20.17 \\
\hline 2 & Вьетнам & 23.33 & 17.59 \\
\hline 3 & Турция & 31.81 & 17.06 \\
\hline 4 & ЮАР & 21.01 & 16.96 \\
\hline 5 & Бразилия & 22.63 & 16.76 \\
\hline 6 & Мексика & 21.37 & 15.88 \\
\hline 7 & Аргентина & 19.69 & 15.40 \\
\hline 8 & Польша & 24.01 & 14.53 \\
\hline 9 & Нигерия & 16.87 & 14.39 \\
\hline 10 & Франция & 16.81 & 11.97 \\
\hline 11 & Нидерланды & 17.66 & 11.90 \\
\hline 12 & Российская Федерация & 18.54 & 11.71 \\
\hline 13 & Таиланд & 15.83 & 11.40 \\
\hline 14 & Германия & 15.21 & 10.97 \\
\hline 15 & Норвегия & 11.75 & 10.45 \\
\hline
\end{tabular}

Снижение темпов прироста количества смартфонов объясняется целым рядом причин. В развитых странах за 5 лет был достигнут показатель 50-70 смартфонов на 100 жителей страны, после чего темпы прироста чис- 
ла новых пользователей снизились, большая часть продаж в настоящее время приходится на тех, кто уже владеет смартфоном. При этом пользователи выбирают модели более высокого качества, удлиняя цикл смены смартфонов. Хотя спрос на новые функции, 4G-подключение и лучшее качество съемки камер оставался высоким, новые поколения смартфонов обладали лишь небольшими дополнительными преимуществами при достаточно высокой цене, что также вызвало сокращение продаж смартфонов.

В данной работе исследуется диффузия смартфонов в зависимости от социально-экономических факторов, в том числе от уровня неравенства доходов. По выборке из 40 стран (США, Япония, Россия, Великобритания и др.) рассчитаны коэффициенты корреляции между количеством пользователей смартфонов в расчете на 100 жителей страны за 2016 г. и следующими показателями: ВВП на душу населения за 2016 г. в постоянных ценах 2011 г., долл.; индексом развития телекоммуникационной инфраструктуры; индексом развития человеческого капитала и др. (табл. 2).

Таблица 2. Коэффициенты корреляции между социально-экономическими показателями и количеством пользователей смартфонов на 100 жителей страны, по 40 странам мира, 2016 г. (данные [10,11,12]).

\begin{tabular}{|l|c|}
\hline \multicolumn{1}{|c|}{ Показатели, 2016 г. } & Коэффициент \\
\hline Индекс развития электронного правительства & 0.902 \\
\hline Индекс развития телекоммуникационной инфраструктуры & 0.891 \\
\hline Индекс развития человеческого капитала & 0.873 \\
\hline ВВП на душу населения в ценах 2011 г., долл. & 0.848 \\
\hline Индекс развития онлайн-сервиса & 0.67 \\
\hline Средняя скорость мобильного подключения к интернету, Мб/с & 0.582 \\
\hline
\end{tabular}

Полученные оценки показывают, что наиболее высокий коэффициент корреляции выявлен между показателем количества пользователей смартфонов на 100 жителей страны и индексом развития электронного правительства (EGDI, [12]), а из составляющих этого показателя с индексом развития телекоммуникационной инфраструктуры (ТCI) и индексом развития человеческого капитала (HCI), а также с ВВП на душу населения.

Была разработана следующая модель зависимости уровня распространения смартфонов на 100 жителей страны $i\left(Y_{i}\right)$ от социальноэкономических факторов: 


$$
\begin{gathered}
Y_{i}=9.3 \cdot X_{1 i}+23.1 \cdot X_{2 i}+45.3 \cdot X_{3 i}-96.6, R^{2}=0.88, \\
\quad(2.9)
\end{gathered}
$$

где $X_{1 i}$ - логарифм ВВП на душу населения в ценах 2011 г. в стране $i, X_{2 i}$ индекс развития телекоммуникационной инфраструктуры в стране $i, X_{3 i}-$ индекс развития человеческого капитала в стране $i$ (в скобках здесь и далее указаны t-статистики). При этом коэффициент зависимости количества смартфонов на 100 человек жителей страны от индекса развития человеческого капитала (45.3) почти в два раза выше, чем от индекса развития телекоммуникационной инфраструктуры (23.1).

Моделирование диффузии мобильных устройств по регионам Российской Федерации. Распространению смартфонов в России способствуют такие факторы, как низкая стоимость услуг мобильной связи, более доступные цены на смартфоны, достаточно высокая скорость широкополосной мобильной связи, широкое распространение бесплатных сетей Wi-Fi. При этом существуют значительные диспропорции в развитии инновационного и кадрового потенциала регионов России, что также влияет на скорость распространения новых технологий [13-18].

Распространение смартфонов в регионах России оценено по двум выборкам: по 14 регионам за 1 полугодие 2011 г. (Москва и Московская область, Санкт-Петербург и Ленинградская область, Краснодарский край, Тюменская область и др.) и по федеральным округам (ФО) Российской Федерации за 1 полугодие 2017 г.[19].

Для выборки из 14 регионов Российской Федерации за 1 полугодие 2011 г. исследовалось влияние различных социально-экономических факторов, а также развитость ИТ-инфраструктуры на удельные месячные продажи смартфонов в расчете на 100 жителей региона (табл. 3). Была выявлена наиболее высокая положительная корреляция удельных месячных продаж смартфонов со среднедушевыми денежными доходами населения, ВРП, долей жителей региона, имеющих образование выше среднего и отрицательная - с уровнем безработицы в регионе.

В результате исследования получена модель следующего вида:

$$
Y_{i}=0.0023 \cdot X_{1 i}-0.024 \cdot X_{2 i}+0.52, R^{2}=0.73,
$$

где $Y_{i}$ - удельные продажи смартфонов в регионе $i, X_{1 i}$ - среднедушевые денежные доходы населения региона $i, X_{2 i}$ - уровень безработицы в регионе $i$. 
Таблица 3. Коэффициенты корреляции между удельными месячными продажами смартфонов на 100 человек жителей региона и соответствующим показателем, 2011 г. (рассчитано по данным [20-23]).

\begin{tabular}{|l|c|}
\hline \multicolumn{1}{|c|}{ Социально-экономические показатели регионов, 2011 г. } & $\begin{array}{c}\text { Коэффициент } \\
\text { корреляции }\end{array}$ \\
\hline Среднедушевые денежные доходы & 0.718 \\
\hline $\begin{array}{l}\text { Доля жителей региона, имеющих образование выше среднего } \\
\text { (на 1000 жителей) }\end{array}$ & 0.706 \\
\hline Индекс готовности регионов к информационному обществу & 0.694 \\
\hline $\begin{array}{l}\text { Число абонентов мобильного доступа к Интернету в расчете } \\
\text { на 100 чел. населения }\end{array}$ & 0.656 \\
\hline Индекс развития человеческого капитала & 0.537 \\
\hline Уровень безработицы,\% & -0.702 \\
\hline
\end{tabular}

Для выборки, состоящей из федеральных округов Российской Федерации с выделением Москвы и Санкт-Петербурга, получен наиболее высокий положительный коэффициент корреляции между количеством смартфонов на 100 жителей ФО и долей занятых в экономике, имеющих высшее образование (0.886), среднемесячными денежными доходами населения (0.748) и уровнем проникновения мобильного интернета (0.732). В то же время выявлена отрицательная корреляция удельных месячных продаж смартфонов с уровнем безработицы $(-0.533)$ и долей лиц, ежедневно использующих интернет, в общем количестве пользователей интернета (-0.398, рассчитано по данным [23-25]). Для ФО России за 1 полугодие 2017 г. построены следующие модели:

$$
\begin{aligned}
\mathrm{Y}_{\mathrm{i}}= & 0.54 \cdot \mathrm{X}_{1 \mathrm{i}}+37.9 \cdot \mathrm{X}_{2 \mathrm{i}}-43.7, \mathrm{R}^{2}=0.89 \\
\quad(4.9) & (2.3) \quad(-3.3) \\
\mathrm{Y}_{\mathrm{i}}= & 0.35 \cdot \mathrm{X}_{3 \mathrm{i}}-46.8 \cdot \mathrm{X}_{4 \mathrm{i}}+37.1, \mathrm{R}^{2}=0.80 \\
& (4.3) \quad(-2.7)
\end{aligned}
$$

где $Y_{i}$ - количество смартфонов на 100 жителей ФО $i ; X_{1 i}$ - доля занятых в экономике, имеющих высшее образование; $X_{2 i}$ - доля домохозяйств, имеющих ПК с подключением к интернету; $X_{3 i}$ - среднемесячные денежные доходы населения ФО $i ; X_{4 i}$ - доля лиц, ежедневно использовавших интернет, в общем количестве пользователей интернета в ФО $i$. 
Заключение. Проведенное исследование выявило положительную корреляцию между распространением новой мобильной техники (на примере смартфонов) и уровнем доходов населения, развитостью телекоммуникационной инфраструктуры (включая распространение и доступность, а также скорость подключения мобильного интернета), индексом человеческого капитала как по странам, так и по регионам Российской Федерации.

Для федеральных округов и регионов России выявлена отрицательная корреляция между количеством проданных смартфонов на 100 жителей региона и уровнем безработицы. Для федеральных округов России выявлена отрицательная корреляция между удельными продажами смартфонов и долей лиц, ежедневно выходящих в интернет, в общем количестве пользователей интернета.

\section{СПИСОК ЛИТЕРАТУРЫ}

1. The Radicati Group Inc (2014): Mobile Statistics Report, 2014-2018, Palo Alto, CA, USA.

2. Internet Stats and Facts in 2018. URL: https:/hostingfacts.com/internet-facts-stats/

3. Digital economy outlook 2015. BBVA Research. URL: www.bbvaresearch.com

4. Social Media Use Continues to Rise in Developing Countries but Plateaus Across Developed Ones URL: http://www.pewglobal.org/2018/06/19/social-media-usecontinues-to-rise-in-developing-countries-but-plateaus-across-developed-ones/

5. Fox S., Duggan M. Tracking for Health. URL: http://www.pewinternet.org/2013/01/28/tracking-for-health/

6. Варшавский Л.Е. Моделирование динамики ключевых показателей рынков компонентов высокопроизводительных вычислительных систем // Труды ИСА РАН. Том 67. 1/2017. - С. 12-27.

7. Вариавский Л. Е. Социально-экономические проблемы, связанные с технологиями ИКТ и искусственного интеллекта // Научно-практический журнал "Конщепщии". 2018. 1(37). с.53-63.

8. Дубинина М.Г. Анализ и моделирование диффузии облачных вычислений в России и за рубежом // Труды ИСА РАН. 2017. т.67, вып. 4. с.22-34.

9. Дубинина М. Г. Моделирование диффузии прогрессивных технологий (на примере технологий фиксированного и мобильного широкополосного подключения к интернету) // Вестник ЦЭМИ РАН (электронная публикация). 2018. № 2. DOI: 10.33276/S0000029-4-1. 
10. Most Americans Already Using Artificial Intelligence Products URL: https://news.gallup.com/poll/228497/americans-already-using-artificialintelligence-products.aspx

11. Liu C. Worldwide Internet and Mobile Users: EMARKETER'S Updated Estimates For 2015.

12. UN E-Government Knowledgebase.

URL: https://publicadministration.un.org/egovkb/en-us/About/Methodology

13. Варшавский Л.Е., Дубинина М.Г., Петрова И.Л. Проблемы развития кадровой составляющей научного потенциала в России и за рубежом. // Научнопрактический журнал "Концепции". 2007. №1(18). с. 12-27.

14. Яркин А.П. Обзор показателей развития научного потенциала России // Haучно-практический журнал "Концепции". 2017. № 1 (36). с.84-86.

15. Никонова М.А. Основные проблемы инновационного развития экономики России // Вестник ЦЭМИ РАН (электронная публикация). 2018. № 2. DOI: $10.33276 / \mathrm{S} 0000065-4-1$.

16. Кочеткова E.B. Социально-экономические факторы снижения выпуска инженерно-технических специалистов с учетом межстрановых сопоставлений // Научно-практический журнал "Конщепчии". 2016. № 1 (35). с. 56-64.

17. Комкина T.A. Особенности подготовки кадров в условиях развития цифровой экономики в России // Анализ и моделирование экономических и социальных процессов: Математика. Компьютер. Образование, 2018. №25 (6). c.107-114.

18. Варшавский А.Е., Кочеткова Е.В. Моделирование показателей спроса и предложения инженерно-технических специалистов // Экономический анализ: теория и практика.2018. т. 17, № 5 (476). с. 886-905.

DOI: $10.24891 /$ ea.17.5.886

19. Akamai. State of the Internet Q1 2017 Report.

URL: https://www.akamai.com/fr/fr/multimedia/documents/state-of-the-internet/q12017-state-of-the-internet-connectivity-report.pdf

20. Евросеть. Пресс-релизы 2017.

URL: https://euroset.ru/corp/pr_information/press_release/

21. Информационное общество: тенденции развития в субъектах Российской Федерации. Выпуск 2: статистический сборник /Г.И. Абдрахманова, Л.М. Гохберг, Г.Г. Ковалева; Нац. исслед. ун-т «Высшая школа экономики». М.: НИУ ВШЭ, 2015.

22. Структура индекса готовности регионов к информационному обществу. URL: http://eregion.ru/reiting-regionov?ind=true 
23. Регионы России. Социально-экономические показатели. 2017: Стат. сб. / Росстат. - Москва, 2017.

24. Мобильный интернет в России. - J'son \& Partners Consulting. URL: http://shtirlitz.com/files/analit/mobile_internet_in_russia.pdf

25. Развитие интернета в регионах России. - Исследования Яндекс. Весна 2016. URL: https://yandex.ru/company/researches/2016/ya_internet_regions_2016.

\section{FACTORS INFLUENCING THE DIFFUSION OF THE NEW MOBILE DEVICES (ON THE EXAMPLE OF SMARTPHONES)}

\section{Dubinina M.G.}

The paper is devoted to the analysis of factors affecting the spread of smartphones in the countries of the world and regions of the Russian Federation, as well as building models of dependence of the number of smartphones per 100 inhabitants on socio-economic indicators (income, level of development of telecommunications infrastructure and human capital). 